\title{
Research on the Influential Factors of the Success of 7-ELEVEn in Japan
}

\author{
Anyi Lyu ${ }^{1}$ \\ ${ }^{1}$ School of Management and Engineering, Capital University of Economics and Business, Beijing, China
}

\begin{abstract}
Developing a new market from a country to another is a challenge for any manager. This study extends to research the new business model of 7-ELEVEn (7-11) that helps 7-11 adapt to different national conditions, grow customer demand and achieve great success in Japan. In this article, mixed methods including quantitative and qualitative study are used to discuss this topic. The business model of 7-11 in the both United States and Japan are investigated, aiming to find the reasons for its success in Japan. From this paper, it can be found that one of the main strategies that 7-11 makes is to develop their core competitiveness includes logistics operation and diversified service, which let them influence the society. Business model canvases in America and Japan are presented in this article, as well. As a result, not only the strategies of 711 but also the spirit of meeting the needs of customers and improving strategy with the trends should be learned by other countries.
\end{abstract}

\section{INTRODUCTION}

In this fast-paced era, convenience stores (CVS) like 7-11 have been distributed globally wide. When people mention about 7-11, 7-11 is well-known by the 7-11 Japan, but few people know that 7-11 belongs to a company from America firstly. The reasons why 7-11 in America was not as well-known as 7-11 in Japan become the first thought of this article. By comparing the strategy canvas between 7-11 in America and Japan, this analysis identifies the revolutionary business models $7-11$ have translated, reflecting how 7-11 managed to achieve the growth of market demand. Most of the primary literature focuses on the revolutionary physical distribution management, and the innovated and favorable information management of $7-11$. However, the social impact of 7-11 is ignored. The social impact that 7-11 brings to the society is regarded as the main reason for the further expansion of customer demand. This article not only summarizes the previous arguments, but also raises a new idea. Inspirations are hoped to bring to the market in other countries like China. In addition, this research aims to fill up the blank in this field.

\section{LITERATURE REVIEW}

\subsection{Business Model Canvas}

In order to make the comparison clearer in the America and Japan, this article will show the business model canvas of 7-11 in these two countries. Business model canvas is a tool that can help entrepreneurs generate ideas, reduce speculation, ensure that they find the right target users and solve problems reasonably[5]. Business model canvas includes nine squares: key partners, key activities, key resources, value propositions, customer relationships, channels, customer segments, cost structures and revenue streams. These nine squares can provide flexible plans and make it easy to satisfy customer demand. This canvas standardize the factors of business models, leading the entrepreneurs find the best solutions.

\subsection{Customer Demand}

Customer demand refers to customers' goals, needs, wishes and expectations. According to Maslow's theory of demand level, human demand level from low to high is physiology, security, social interaction, self-esteem, selfrealization. And the satisfaction of lower demand level is the basis of realizing higher demand level. The emergence and development of any social and economic era is the product of the continuous upgrading, innovation and interaction of productivity development and human demand. In the 21 st century, in the era of "micro innovation", customer demand has become the main creative basis of "micro innovation" of enterprise products From business model canvas, core competitiveness of 711 can be reflected obviously in the canvas. Core competitiveness is the ability of an enterprise to gain competitive advantage for a long time. The core competitiveness of an enterprise can enable the enterprise to win among competitors and satisfy customer demand. 


\section{METHODOLOGY}

Case study is an empirical inquiry that investigates the contemporary phenomenon in its special real-life context. Case study not only describes the phenomenon in detail, but also analyzes the reasons behind the phenomenon, which helps researchers and readers to grasp the context of the case effectively. In addition, case study is suitable for individual researchers, and is easier to understand. Case study is suitable for answering the research questions of how to change, why it becomes like this and how to get results when the boundary between phenomenon and actual environment is unclear and not easy to distinguish, or when researchers cannot design accurate, direct and systematic variables. Considering that this article mainly focuses on the question how to change, case study is very suitable.

By using the method of archival research, this article sums up the content of this article by analyzing the successful case of 7-11 in Japan and the existing data on the Internet.

To formally assess the existing studies relevant to 7-11 convenience store, there are two related websites for Chinese researchers to refer to: China National Knowledge Infrastructure (CNKI) and Baidu Scholar. Using "7-11" as a keyword, there were more than 100 articles and more than 10000 articles published in CNKI and Baidu Scholar. However, there were fewer articles contained data to illustrate some of 7-11's operations than using the word "Japan", "business model" as the second and the third keyword. There were some articles explaining the methods of management and operations 711 did that helped them succeed. And most of these articles focused on the logistics operations. In order to attain more information of the situation in America, Retail Philosophy (written by Toshifumi Suzuki) that recorded a lot of details about the Southland Corporation was read throughout.

To identify the factors of business model canvas and the core competitiveness of 7-11, almost every paper published after 2010 were read. Since most of the literature did not cover relevant data about 7-11, the keywords were directly searched on the Internet, and the recent data from Deloitte Touche Tohmatsu Limited were finally found. Because of the reliability of the source, these data were directly referenced in this article.

\section{ANALYSIS}

\subsection{Background of 7-11 Convenience store}

In Japan, convenience stores have produced a kind of culture and bring a large range of profits to the market. Nowadays, growing citizens are keen on purchasing in 711 even though the average cost performance is lower than similar products provided in normal supermarkets and restaurants. 7-11 has become the world's largest convenience store brand, far larger than Lawson and FamilyMart, the other two of the country's biggest three convenience stores. Until February 2019, there were about 20,900 7-11 stores in the region, far outnumbering Lawson and FamilyMart. Globally, excluding Japan, 7-11 had 47,360 stores in the top three countries: Thailand, South Korea and the US [1].

Before 7-11 became popular in Japan, 7-11 was first established by the Southland Corporation, a company from America, and at that time of 1927, the concept of convenience store appeared initially: sell ices for customers to cold storage the food as well as providing milk, bread and eggs on Sundays. In 1946, the Southland Corporation formally changed their name into 7-Eleven INC, opening the stores from 7 am to $11 \mathrm{pm}$. In 1973, a Japanese named Toshifumi Suzuki took over the franchise of 7-11 in Japan and formally founded 7-11 in Japan. In 1987, the Southland Corporation failed to expand diversification and declared bankruptcy. Then in 1991, Ito-Yokado, a Japanese retailer, bought $73 \%$ of the Southland Corporation and became its largest shareholder.

Decades later, the original American Southerland Corporation, as the founder of 7-11, offered to let 7-11 Japan take over all the stores in the United States. The effort Suzuki had made and create to help 7-11 success and take over all the stores in America was built their own business model.

\subsection{Business Model Canvas}

Table1. Business Model Canvas of 7-11 in America

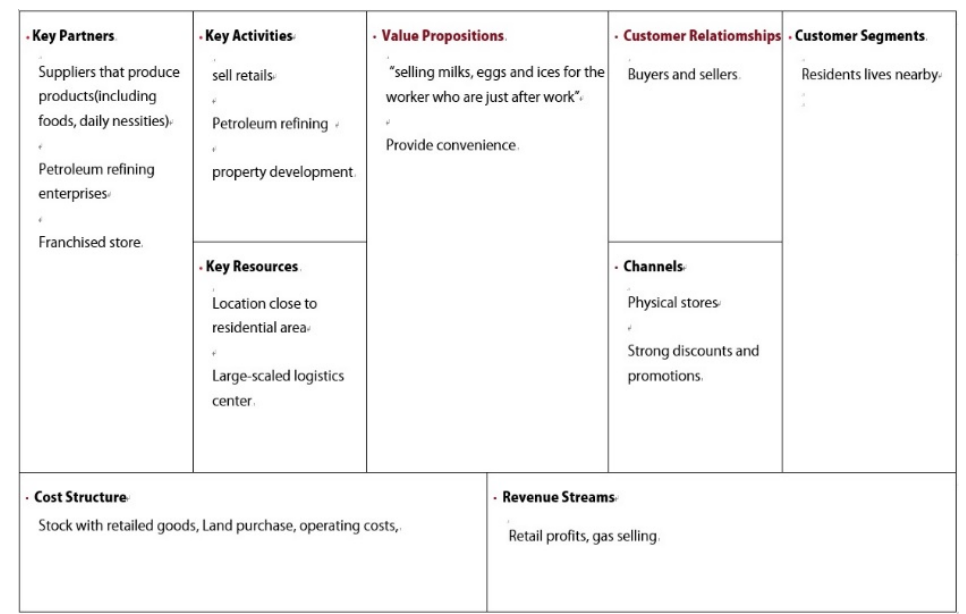


Table2. Business Model Canvas of 7-11 in Japan [2]

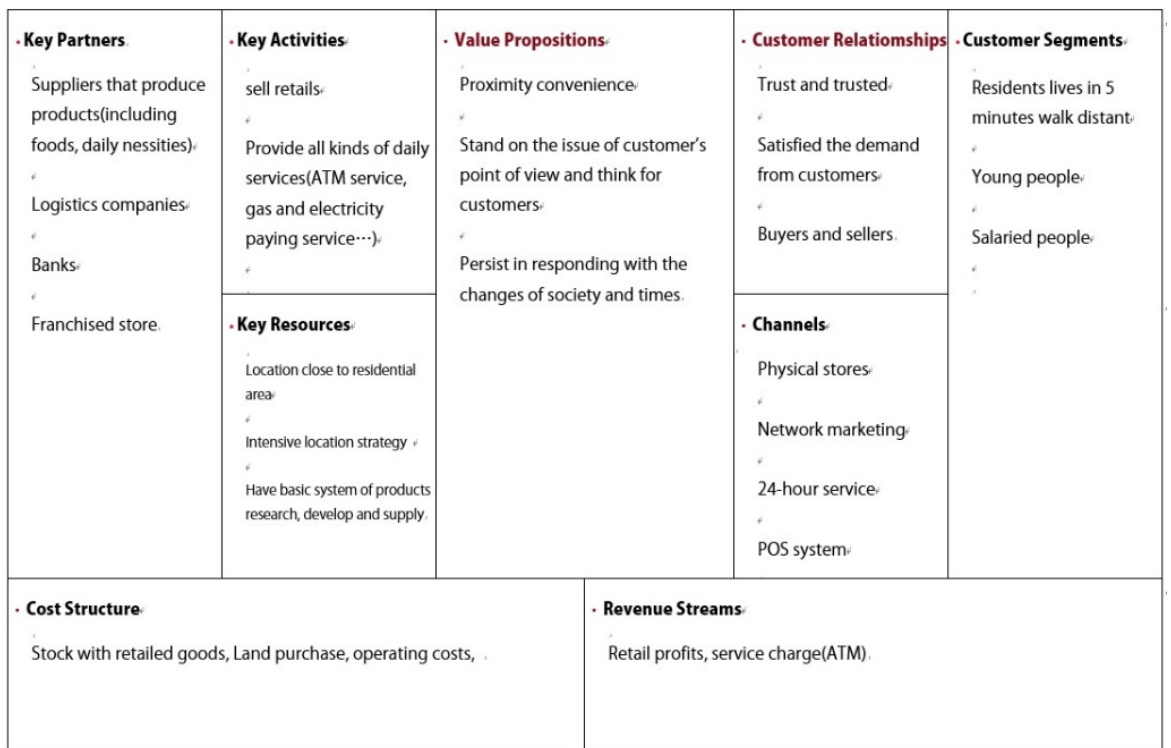

As shown in table 1, the customer segments are located in the nearby residents, and they need all sorts of products to meet the needs of daily life. In order to get in touch with the residents, 7-11 America established physical retail stores near residential areas and offered some discounts and low prices to attract customers and compete with similar supermarkets. At the same time, because many other convenience stores had gas stations or were located near the gas stations, 7-11 America also involved itself in the oil refining industry. With its convenient location and the potential of new enterprises, it is easy to contact many suppliers.

It can be seen from table 2 that 7-11 Japan's target customers are not only residents in 5 minutes-walk distant, but also salaried people and young people. Salaried people are usually very tired and late after work. Instant food and heated food in the convenience store can save them from the trouble of waiting in the restaurant, so that they can get home in time and eat hot food. Young people are more receptive to new things, and this new business model can make them interested. 7-11 Japan provides a variety of services for its customers, and also attracts customers through the operation of retail physical stores, so as to make profits from retail and customer service. They get business qualification from suppliers and banks, and their products are positioned at a higher price than normal markets.

From these two tables, it can be concluded that 7-11 Japan has created its own new value under the basic mode of 7-11 America. As it can be seen from Key Activities, 711 America not only does retail business, but also involves the oil refining industry, while Japan has developed various services for customers. 7-11 America chose to involve the oil refining industry and the real estate industry when it was not satisfied with only operating convenience stores which led to the failure of its diversified expansion. And 7-11 Japan always carries out the concept of satisfying customer demand, optimizes the business model in its own field, and provides convenience for customers. 7-11 Japan has developed its unique core competitiveness, not only the logistics operation and diversified services described below, but also its employee management and location strategy, and only logistics operations and diversified service are discussed below. Both America and Japan have added several new services, but 7-11 of America is not as popular and recognized as it is in Japan. One of the reason is that many convenience store in America have already added the service of gas station and the industry of oil refining, they were just catching up with the former stores while 7-11 of Japan was developing new service for customers. 7-11 of America has many other competitors and it is not unique enough for Americans to choose the service, while 7-11 of Japan is the one who creates many new service and has earned a lot of trust and loyalty among Japanese.

\subsection{Core Competitiveness}

4.3.1 Logistics Operation. Due to the prosperity of large stores, the current social situation in Japan is that small and medium-sized retail stores are in a recession. In the past, Suzuki insisted on introducing 7-11 into Japan and created a new business model that allows them to coexist and prosper. As the result, 7-11 has taken a different approach from traditional private stores, aiming at improving production efficiency and product value, and established a unique business structure.

At first, one of the main operation 7-11 has done to fit in the context is to distribute in a small amount. At the beginning of the first store opening in Japan, the most distressing problem was how to reduce the large amount from inventory. At that time, the tradition of ordering products was purchasing goods in large quantities from the wholesalers until the supply was running out. This caused a large number of bad inventory in storage, hindering the further improvement of turnover. Hence, Suzuki made a great effort on persuading wholesalers to change their reluctant tradition [4].

Nowadays, just-in-time logistics (JIT Logistics), a thorough logistics operation has implemented, including 3 concepts: deliver in small amount, an advanced logistics 
system and 3 steps of distribution. Direct delivery by the wholesalers, intensive distribution and joint distribution, the 3 steps of distribution, helped to reduce not only the number of wholesalers and the cost of delivery but also reduce the storage, providing customers fresh foods and goods. For example, in order to make the goods more specific and well-organized, 7-11 classifies the foods into 3 types according to the needed temperature: freeze temperature $\left(-20^{\circ} \mathrm{C}\right)$, cold temperature $\left(5^{\circ} \mathrm{C}\right)$, room temperature and warm temperature $\left(20^{\circ} \mathrm{C}\right)[1]$. From raw materials to finished products, 7-11 establishes a database to control and trace the whole process of purchasing, transportation and production of raw materials, so as to ensure the quality of food.

Table3. Temperature Distribution

\begin{tabular}{|lll|}
\hline Temperature & Suitable Products & Distribution Frequency \\
\hline frozen & Ice, ice cream, frozen food... & $3-7$ times/week \\
\hline cold & Sandwiches, milk, vegetables... & 3 times/day \\
\hline room temperature & Canned food, drinks, snacks... & everyday \\
\hline warm & Roasted bread, cooked food... & 3 times/day \\
\hline
\end{tabular}

This operation mode ensures the freshness of the food to a large extent. Because of the fresher goods providing from 7-11, people who eagerly have the needs of food like salary earners have just off their duty are attracted to purchase in convenience stores. These operations not only reduce the cost of distribution, but also ensure that customers can get the freshest food in a short distance.
11 store is to give community convenience, letting customers reach their store in 5-10 minute-walk distance. Besides buying the goods, other needs are solved at the same time. Except for selling foods and goods, ATM service, printing service, ticket service, fee collection and other services are also provided by 7-11 to satisfy customers' demand.

\subsubsection{Diversified Service. The purpose of opening a 7-}

Table4. 7-11 Convenience Service

\begin{tabular}{|ll|}
\multicolumn{2}{|c|}{ Service Types } \\
\hline traditional convenience & print and copy, fax, express delivery... \\
\hline digital and telecommunications & cellular phone replenishing, game point card, wi-fi card... \\
\hline tickets & sports lotteries, concert tickets, exhibitions tickets... \\
\hline food deliver & Seven-Meal service \\
\hline life service & water, electricity and gas payment \\
\hline sign up & registration for training sessions \\
\hline financial & ATM \\
\hline
\end{tabular}

According to Suzuki's research, in the 1990s, many customers put forward the request of "add ATM machines in convenience stores" when they were interviewed and answering the questionnaire. In 2001, the bank license was finally give to 7-11 and let them put ATM machines in the store after their great efforts. Subsequently, ATM began to appear in 7-Eleven stores on a large scale, providing convenient financial services for consumers. Since 7-11 is a convenience store that provides customers with necessities of life, customers will naturally regard cash as a "product"[1]. After ATM machines appeared in 7-11, customers' urgent needs of cash were solved. People can get cash from credit card in any 7-11 store instead of going to a bank. Until present, the number of ATM machine is still increasing every year. The number of growing rate indicates the increasing needs of ATMs. 


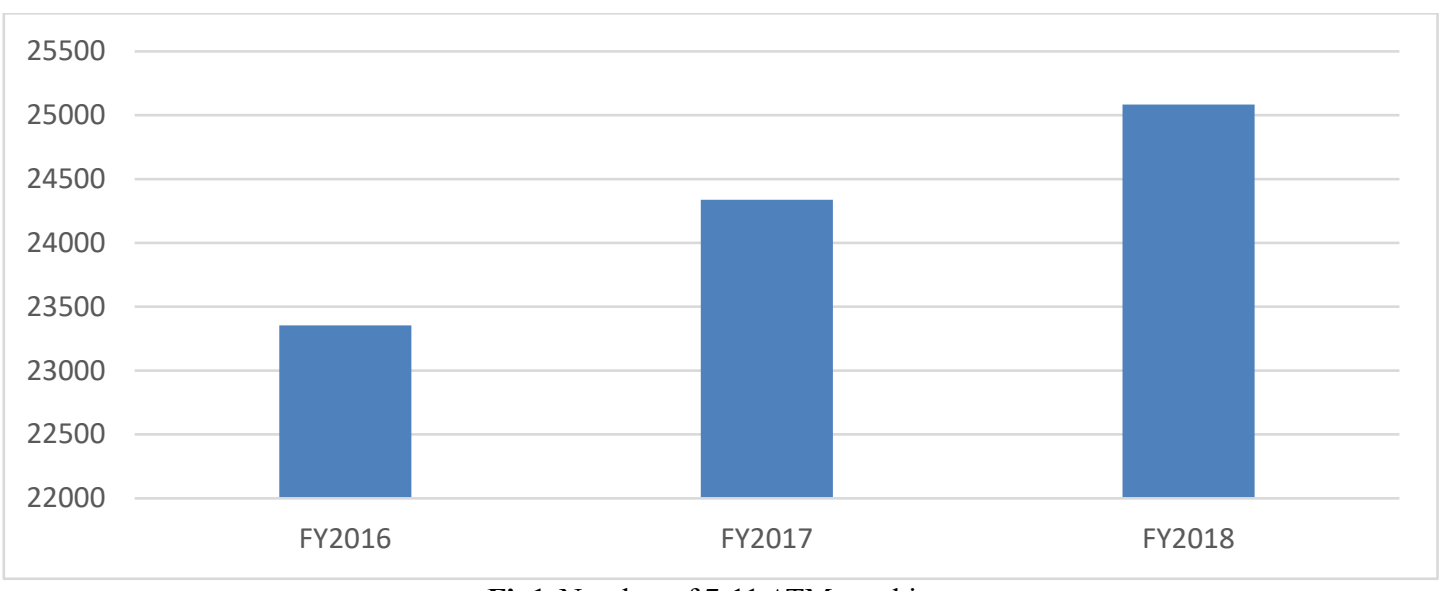

Fig1. Number of 7-11 ATM machines

In 2018, the group had 25083 ATMs in Japan, among which 22114 are set in 7-11 convenience stores, an increase of 633 compared with 2017. On average, each store has one or more ATMs to satisfy consumers' demand of 24-hour convenient cash taking and other services.

Customers are distressed that they have to get to a special financing agency to pay for water, electricity and gas every month when there was no such online payment yet. At the same time, most of the financing agency had weekends and holidays like other companies did, so convenience stores provided payment services and saved them from big trouble.

Apparently, 7-11 provides convenience services by charging a small fee while selling goods, but the truth is the growth sales amount comes from the people who go to stores to get cash and pay the fee first.

\subsection{Social Impact}

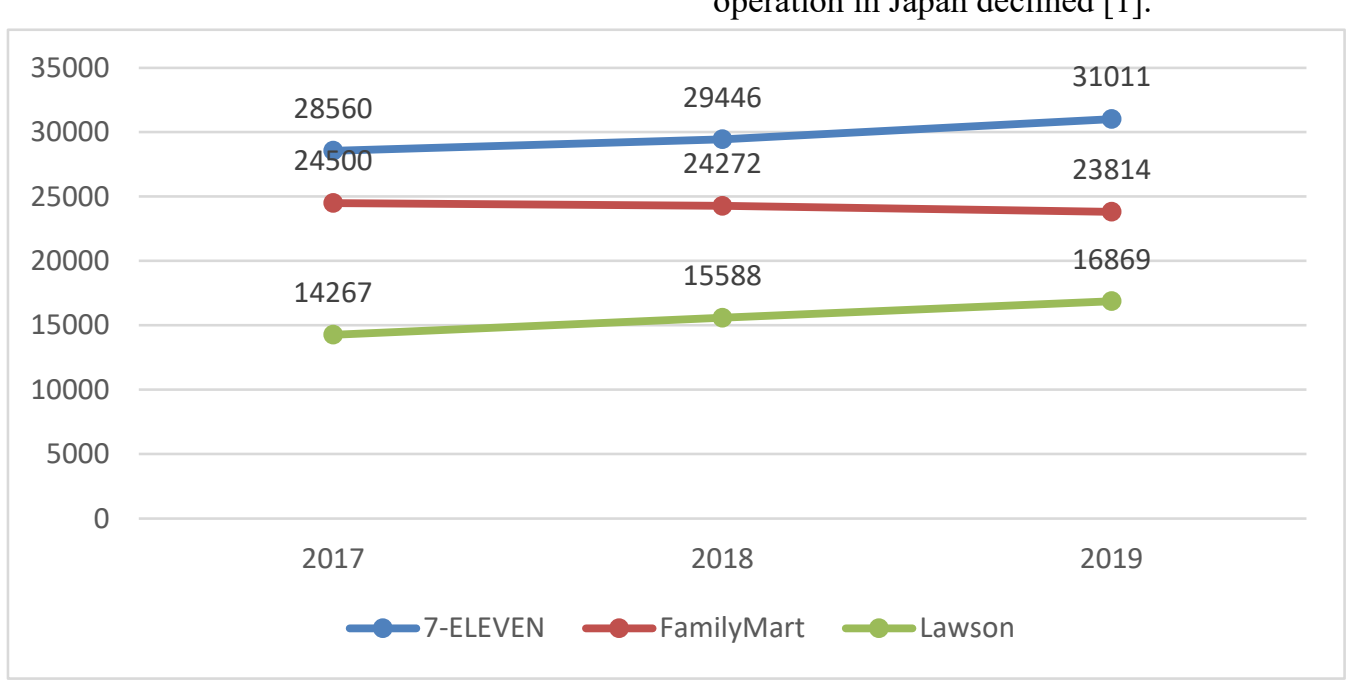

Fig2. Comparison of Number of 3 CVS

It can be seen from figure 2 that even though the convenience store industry has developed until the current situation, a large number of stores are still appearing every year.

Convenience stores are gradually changing people's way of life by catering to the fast pace and sloth of young people since young people between 10-30 years old are the main target customer group. With the improvement of people's consumption level and the increasing rationality
When it comes to modern Japanese culture, the culture of convenience stores is mentioned frequently. The success of 7-11 made many entrepreneurs see the business opportunities. They followed 7-11 and established many similar enterprises, like Lawson and FamilyMart. These enterprises also seek differentiation strategy while following the example of 7-11. For example, Lawson improves the quality and taste of products on the basis of ensuring the normal operation of the supply chain. Under the influence of these enterprises, convenience stores are almost everywhere in Japan. Until February 2019, the number of convenience stores operated by 7-11 Japan (SEJ), a subsidiary of the group, reached 20876, a net increase of 616 over the previous year. The number of stores operated by the FamilyMart in Japan was 16430, a decrease of 993 over the previous year. The number of stores operated by Lawson in Japan was 13738, an increase of 666 over the fiscal year 2018. FamilyMart's operation in Japan declined [1].

of consumers, the original material demand changes to the service demand. Customers no longer focus on good quality and low price, while good value for money is getting more and more important. Instead of going to a department store for a long time, people are shortening the time when they are shopping in stores and pursuing more convenient shopping methods. According to the report [1], about $90 \%$ of the customer control their shopping time within 10 minutes in $7-11$. More than $50 \%$ of the 
customers control their time within 5 minutes. In addition, $65 \%$ of the customers are on their way to work or on the move.

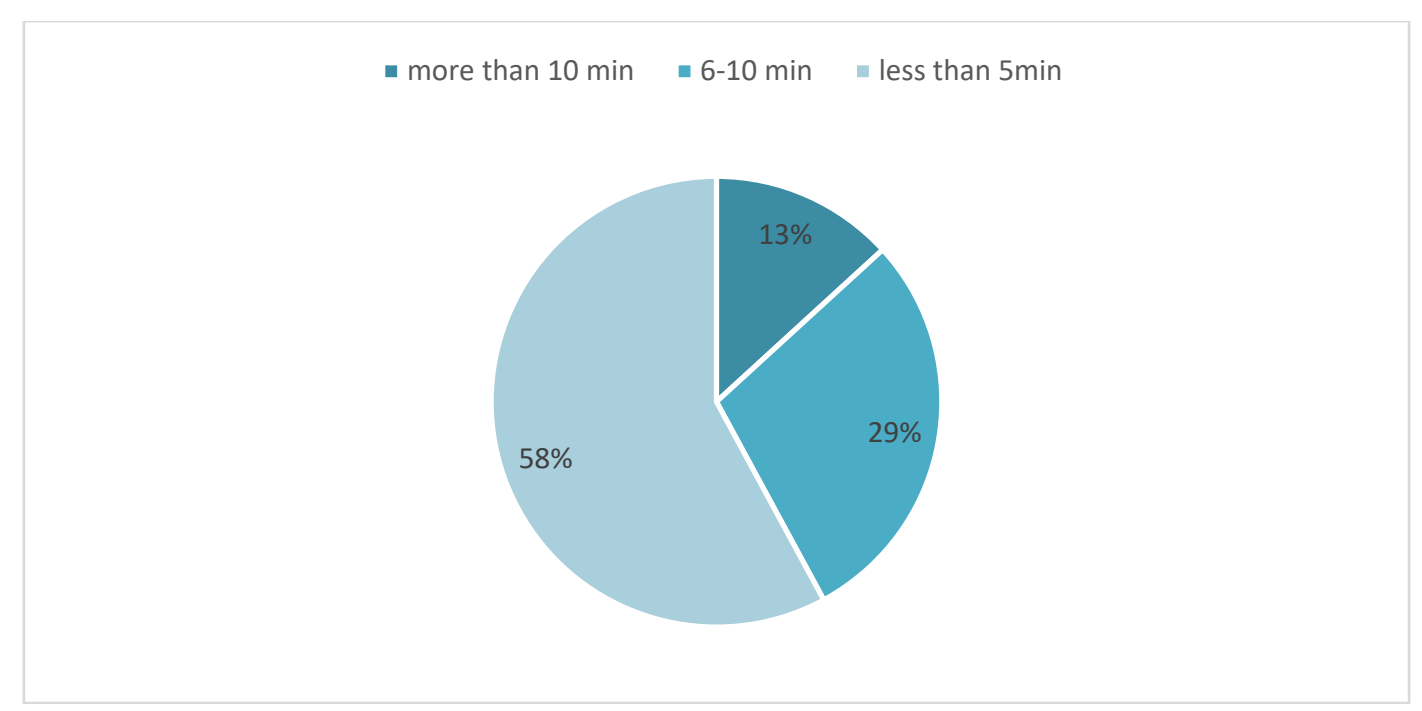

Fig3. Customers' Shopping Time

The establishment of a large number of convenience store enterprises has prompted people to change their way of life, and society has gradually become more convenient and life-oriented.

\section{LIMITATIONS AND SUGGESTIONS}

Due to the limitation of network and copyright, many papers on the Internet cannot be read. Due to the confidentiality agreement of each company, most of the data can only be retrieved on the Internet, and the accurate first-hand information cannot be obtained, so some of the data may not be up-to-date.

According to the previous analysis, convenience stores in China, the United States and even global wide can learn from Japanese convenience stores in many aspects. First of all, convenience stores need to find out customers' real demand and stand on the perspective of customers. Covering the optimized supply chain and the diversified services, the main purpose is to satisfy customers' need of fresh food and quality of life. Regarding the needs of customers as the ultimate goal, they should establish a diversified store where not only sells goods but also sells the service.

To let 7-11 adapt to the variation of society and improve strategies from all aspects, Suzuki went to America to investigate, after he acquired the Southland Corporation of America completely. It was found that all the inventory of goods was forced to give to every single store and lead to a lot of useless goods hoarding in the storage. Referring to the Japanese experience, Suzuki let employees of each store order their products independently according to the demands of customers. This method fully encouraged the enthusiasm and responsibility of employees and reduced unnecessary waste. In addition, the location strategy also makes 7-11 stand out from the competition. The strategy of building the regional centralized store not only conforms to the situation of narrow streets in Japan but also improves the brand effect, logistics and distribution efficiency within a certain area.

\section{CONCLUSION}

Although 711 was born in America, it popularized and developed in Japan. 7-11 of Japan adds the original value of immediacy and convenience to the products, and forms the different positioning and value from the 7-11 of America as well as other large supermarkets. 7-11 sets up regional logistics center for centralized distribution and JIT Logistics, which is jointly invested and established by manufacturers and wholesalers. Besides, it improves the efficiency. Furthermore, based on the demand of community groups, it develops new and diversified services that can bring new customers and enhances the old customers' loyalty. To some extent, 7-11 affects the whole Japanese society and changes some of citizens' habit and lifestyle. On the other hand, the reason that 7-11 can become a symbol of the convenience store industry is because of the essential innovative thinking and the courage of trying. As Suzuki said, the idea that most people opposed would often make success. The experience of 7-11 tells operators from other companies that good logistics management and satisfying customer demand are crucial factors for the success of convenience stores. To start a new business from a country to another, it is significant to create unique business models according to different situations.

\section{ACKNOWLEDGMENT}

First and foremost, I would like to show my deepest gratitude to my teachers and professors in my university, who have provided me with valuable guidance in every stage of the writing of this thesis. Further, I would like to thank all my friends and roommates for their encouragement and support. Without all their enlightening instruction and impressive kindness, I could not have 
completed my thesis.

\section{REFERENCES}

1. Deloitte Touche Tohmatsu Limited, Zhongtai Securities, Research on the Business Model and core competitiveness of 7-Eleven. 2019. Retrieved on: Jul.13th, 2019, pp. 4-38

2. http://www.360doc28.net/wxarticlenew/848546591. html.

3. Y. R. Ji. Looking at American franchising from the Southland Corporation. China Market. 1998, vol. 10, pp. 48-49.

4. J. B. Chen. The ups and downs of 7-11 convenience stores in the United States. Think Tank of Science \& Technology. 1998, vol. 4, pp. 51-54

5. T. Suzuki. Retail Philosophy. Translated by Gu, X. L. Jiangsu Province: Jiangsu Phoenix Literature and Art Publishing, LTD. 2014

6. S. Blank. The One Tool Startups Need to Brainstorm, Test, and Win. First Round and Review. Retrieved on: Feb. 28th, 2017, pp. 1-2 